\title{
Determination of Possible Responses of Radon-222, Magnetic Effects, and Total Electron Content to Earthquakes on the North Anatolian Fault Zone, Turkiye: An ARIMA and Monte Carlo Simulation
}

Dawar Hama Khalid Mohammed

Firat University: Firat Universitesi

Fatih Külahcı ( $\nabla$ fatihkulahci@firat.edu.tr)

Firat University, Nuclear Physics Division https://orcid.org/0000-0001-6566-4308

Ahmad Muhammad

Firat University: Firat Universitesi

\section{Research Article}

Keywords: Radon gas, Total Electron Content, Forecasting, Earthquake, Prediction, ARIMA, Monte Carlo Simulation, Model

Posted Date: February 22nd, 2021

DOl: https://doi.org/10.21203/rs.3.rs-214384/v1

License: (c) (1) This work is licensed under a Creative Commons Attribution 4.0 International License.

Read Full License 


\section{Abstract}

Around the world, earthquake forecasting studies have become very important nowadays due to the increase in number of fatal earthquakes annually. This paper proposes to achieve a possible relationship between soil radon gas concentration and atmospheric Total Electron Content (TEC) during earthquakes taking into account magnetic effects on the North Anatolian Fault Zone (NAFZ) in Turkiye. The ARIMA and Monte Carlo Simulation (MCS) are employed for determining radon gas concentrations by taking into account magnetic effects as an innovative approach. In the study area relatively small and medium-scale earthquakes have taken place during the observation period. As a result of the investigations, the relationships between each of the parameters and earthquakes are determined, and hence, a good relationship is obtained between Rn gas anomaly and micro-seismic activity. In the ionosphere, geomagnetic activity has a primary impact and long duration on TEC distribution, but due to microseismic events it has rather small influence. The proposed ARIMA and MCS simulations to detect changes in soil Rn gas concentrations have significant results for detecting micro-seismic activity anomalies.

\section{Introduction}

Earthquake forecasting studies have become very popular recently, especially in the last five years, huge earthquakes have started to occur worldwide with magnitudes more than 7 . Scientists hope to be able to predict earthquakes to keep society away from death and injury. The relationship of ${ }^{222} \mathrm{Rn}$ with earthquakes have been studied individually by scientists (Kamislioglu and Külahcı 2014; Külahcı and Şen 2014; Külahcı and Çiçek 2015; Kamislioğlu and Külahcı 2016; Külahcı 2020) but research on the relation between earthquakes, ${ }^{222} \mathrm{Rn}$, and atmospheric TEC is an extensive and very complicated research area. Requirement to combine joint experience in different fields is necessary, such as seismology, atmosphere with ionosphere physics, and geomagnetic activity (Le et al. 2013). In the earth's crust, most of the rocks and grains contain uranium element and since radon gas is a part of the uranium $\left({ }^{238} \mathrm{U}\right)$ decay chain, they are continuously produced in the soil. Most of the ${ }^{222} \mathrm{Rn}$ emissions can be detected in the earth's crust, and they can move large distance in the earth and atmosphere (Nazaroff and Nero 1988; Scholz 2019). It is well-known that one of the important and most often used precursory for predicting earthquakes is ${ }^{222} \mathrm{Rn}$ gas detection (Rikitake 1968; Ghosh et al. 2009; Külahcı and Çiçek 2015; Muhammad et al. 2020; Papastefanou 2007). First research about pre-earthquake ${ }^{222} \mathrm{Rn}$ anomaly was observed in 1966 for the Tashkent City of Uzbekistan earthquake ( $M=5.2)$ capital, where the study area was monitored over 6 years before the earthquake, and these observations indicated increasing ${ }^{222} \mathrm{Rn}$ concentration until the earthquake occurrence time. In China (1976), before some severe earthquakes occurrences, unusual changes were observed in radon gas (Ulomov et al. 1967; Ulomov and Mavashev 1967; Kuo et al. 2011; Friedmann 2012). Rn concentrations were determined in fault lines higher than normal soils (Singh et al. 1999). 
Ionospheric anomalous due to seismic events is another precursory acceptance by scientists. Research on this subject is rapidly increasing in the last decade. Prior to high magnitude earthquake occurrences, mechanical energy is accumulated in the plates, which causes to positive and negative ions generations through compression of the rocks in the ground, and Acoustic Gravity Waves (AGW) through earth crust motion and hotbed gases emission of into the atmosphere (Miyaki et al. 2002; Liperovsky et al. 2008; Md Yusoff and Hwee San 2016). These processes from the ground to air atmosphere can cause for temperature rise, pressure rise in the troposphere. TEC perturbation in ionosphere occurs with variation in an earthquake precursory (Shah et al. 2019; Tariq et al. 2019; Xia et al. 2011). One of the significant in investigation about ionosphere is observable TEC parameter. TEC monitoring provides a direct link to connect to atmospheric activity and causes for understanding the complex phenomena that occurs in the ionosphere and plasmasphere. TEC is defined as an electron density profile amount between two points in a cylinder tube of $\left(1 \mathrm{~m}^{2}\right)$ cross-sectional area, which corresponds to the total number of electrons. The TEC unit is defined as (TECU) and 1 TECU $=10^{16}$ electron $/ \mathrm{m}^{2}$ (Nayir et al. 2007; Simha et al. 2014; Xia et al. 2011). Determination of the reasonable effects on the ionospheric parameters variation is important. The influences of geomagnetic activity are very essential from above and seismic activity below the ionosphere (Bhattarai et al. 2016). Solar winds carry the sun's energy and transfer it into the earth's magnetosphere and as a result geomagnetic storms generation occurs (Spruit and Roberts 1983). During geomagnetic field disturbance, a huge amount of energy enters into the earth magnetosphere and ionosphere, which causes to ionospheric parameter changes, such as composition, temperature, and height changes (Bhattarai et al. 2016). The first seismo-ionospheric copulation study was recorded in 1964 about the Alaska earthquake (Davies and Baker 1965; Leonard and Barnes Jr 1965). After about 20 years later satellite data are used for seismo-ionospheric investigation in the early 1980s (Gokhberg 1983). On 17 Jan 1994 for the first time (GPS) technology was used during the earthquake in $M_{w}=6.7$ Northridge (Calais and Minster 1995).

The ARIMA method or the Box-Jenkins method (1960-1970) was found after the two statisticians George Box and Gwilym Jenkins, who applied a model to find the best fit of a time-series to past values of a time series data. ARIMA method is derived from Auto-Regressive Integrated Moving Average (Box et al. 2011; Ho and Ting 2015). Based on the past values of a data time-series information, ARIMA method simulation can be made about future values. Simulation models produce an effective estimating to find unknown quantities so that this technique is valuable to estimate and forecast soil radon concentration (Külahcı et al. 2020). The MCS is a probabilistic method; it is useful for predicting future values of a variable. The basic idea behind the MCS method is to run simulations to get the probability distribution of all possible outputs with the best and worst scenarios (Farrance and Frenkel 2014). The first work in the literature on the Monte Carlo was published by applying Monte-Carlo techniques on the measurement of the spectra Bremsstrahlung photon beam of radiotherapy by using the Sodium lodide ( $\mathrm{Nal}$ ) detector from Bentley et al (1967) (Bentley et al. 1967). The use of the Autoregressive Integrated Moving Average (ARIMA) method together with Monte-Carlo Simulations (MCSs) technique is a rather new technique and it is the first time used for prediction in this field with these parameters. 
The objective of this study is to determine a possible relationship between ${ }^{222} \mathrm{Rn}$ gas concentration and TEC variations with earthquakes by considering magnetic effects, and studying all variables jointly. Another innovation is that ARIMA and Monte Carlo simulations help to identify a model variation and ${ }^{222} \mathrm{Rn}$ concentration prediction on the North Anatolian Fault Zone (NAFZ), Turkiye.

\section{Data Sources And Method Of Analysis}

The North Anatolian Fault Zone (NAFZ) is one of the most famous dextral strike-slip faults, especially in Turkiye, and generally, in the Eastern Mediterranean region because of its significant seismic activity (Akin et al. 2013). The NAFZ stretched $(1200 \mathrm{~km})$ from Saros Gulf in the Northern Aegean Sea to the Karliova triple junction in Eastern Anatolia and have a broad arc-shape. It forms a border between Anatolian and Eurasian plates almost parallel to the Black Sea coast maintaining a relatively regular distance of $100 \mathrm{~km}$ from the coast (Akin et al. 2016; Bayrak et al. 2011; Bozkurt 2001). The study area, Yolkonak station is shown in Figure 1.

The study area, Yolkonak station is located $37 \mathrm{~km}$ north-east of the Tokat city center at $40.53932 \mathrm{~N}$ 36.89443E on the eastern part of the seismically active NAFZ segment and the left embankment of the Kelkit River, the altitude from sea level is $355 \mathrm{~m}$. NAFZ has high seismic activity for posing a high risk to areas that have a high population around the fault. It is very important for the understanding of large strike-slip fault systems (Bayrak et al. 2011). Study area elevation 3D graphs are shown in Figure 2.

\subsection{Earthquake Measurement}

The seismic activity in the Tokat-Yolkonak region during the observation period between 2007-2010 can be obtained from the Bogazici Kandilli Observatory (http://www.koeri.boun.edu.tr/scripts/lasteq.asp). A total of 54 earthquakes in a circle with $150 \mathrm{~km}$ radius around the station were recorded and 29 earthquakes with a magnitude between $M_{L}(2.6-4.7)$ at prediction range of data. The largest one is $M_{L}=$ 4.7, which occurred inside the observation area.

\subsection{Radon Measurement}

Rn gas concentration data for period 2007-2010 in the study area is donated by the AFAD-Ministry of Interior Disaster and Emergency Management Presidency (https://en.afad.gov.tr/). Data transferred to the center from all online stations. In the present study, the online ${ }^{222} \mathrm{Rn}$ measurement system consists of the detector (Alpha Meter 611, manufactured by Alpha Nuclear Co., Canada), power source, data logger unit, and global system mobile communication (GSM) modem (Thomas et al. 1992). Soil ${ }^{222} \mathrm{Rn}$ gas was deliberated continuously every $15 \mathrm{~min}$ interval by using alpha meter detectors. The radon gas emanation variation and earthquakes for the study period are showed in Figure 3. 


\subsection{Total Electron Content (TEC)}

In this study, Total Electron Content (TEC) collected through lonospheric Research Laboratory-Turkiye (IONOLAB) (http://www.ionolab.org/index.php?page=index\&language=en), where the near real-time online computation of Total Electron Content (TEC) is provided (Arikan et al. 2003; Sezen et al. 2013).

The nearest and available TEC stations for the period (01 Mar 2007 to 12 Feb 2010) from the study area are three stations (Ank, Tubi, and Ista). The TEC daily data are recorded at every $2.5 \mathrm{~min}$ for a single and multiple-station computation in the range of consecutive days. The upper and lower bounds are obtained through the statistical equation $(\mu \pm 2 \sigma)$, where $\mu$ is the mean and $\sigma$ is the standard deviation for 10 days before and 5 days after the event (Shah et al. 2019).

\subsection{Solar Geomagnetic Activity}

Three important parameters are global geomagnetic activity $\left(K_{p}\right.$-index), disturbance time storms $\left(D_{s t}\right)$, solar flux (F10.7) are used in this study to explain the effects of the geomagnetic activity on the ionospheric TEC. The parameters are obtained from OMNI internet-based data through explorer system project developed by (NASA) (www.omniweb.gsfc.nasa.gov). These parameters are global geomagnetic activity ( $\mathrm{K}_{\mathrm{p}}$-index), which defines the earth's magnetic field disturbance caused by the solar wind, and it values are between $10-90$. When its value is below 40 then the condition is considered as quiet, $K_{p^{-}}$ index value multiplied by 10 in this study (Menvielle and Berthelier 1991). Disturbance time storms $\left(D_{s t}\right)$ show the geomagnetic activity in one-hour time, when $D_{\text {st }}$ value between is in the range -20 and $20 \mathrm{nT}$, and this condition is considered as quiet geomagnetic (Cander and Mihajlovic 1998). The solar flux (F10.7) has unit sfu (solar flux unit $=10^{-22} \mathrm{~W} \mathrm{~m}^{-2} \mathrm{~Hz}^{-1}$ ) and it defines the density of a microwave flux having $10.7 \mathrm{~cm}$ wavelength when the F10.7 value is below (70 sfu), and the condition is considered as a quiet (Guo et al. 2015).

\section{Results And Discussion}

Rn gas concentration is monitored continuously for about three years from 2007 to 2010 as a capable precursor of seismic activity at NAFZ. All data are used in this study equal to $(103,235)$ radon data for every 15 min interval. Prior to the ARIMA and MCS methods application, the data is divided into train and test parts as $80 \%$ and $20 \%$, respectively. The test prediction part occupies $20 \%$ in the tail of data, which is used to evaluate accuracy of the model in the prediction.

To determine the best model for data time series, Box-Jenkins recommended assurance of stationarity in time series. For this reason, more than one test it taken into consideration to assure the time series stationarity (Kwiatkowski et al. 1992), such as the KPSS test, augmented Dickey-Fuller (ADF) test, skewness test, (one-sample and paired-sample) t-test, and Leybourne-McCabe test (Cheung and Lai 1995; Hobijn et al. 2004; Leybourne and McCabe 1994). After checking the results of (KPSS test, Leybourne- 
McCabe, skewness-test, and t-test) it is observed that all support that the data is non-stationary despite ADF test. Hence, it is necessary to take the differentiation until the series becomes stationary. The same is valid for above-mentioned tests for radon data differentiation in a second time. After proving the time series data as stationary, the next step is the ARIMA model usage to find the best model fit to the Rn timeseries. Model identification needs to determine values of $p$, and $q$ from lags crossing the confidence significant lags bounds of the PACF (Partial Autocorrelation Function) and ACF (Autocorrelation Function) plot respectively. The ARIMA $(8,1,13)$ model is the most suitable one for the prediction of the future value of ${ }^{222} \mathrm{Rn}$ concentrations and the model has a satisfactory estimate, because simulation values are in good agreement with the real radon values, and the smallest standard deviation belongs to ARIMA $(8,1,13)$ model, which is defined in Equation 3.1 in the below.

$$
\left(1-\phi_{1} \mathrm{~L}-\cdots-\phi_{8} L^{8}\right)(1-\mathrm{L}) y_{t}=C+\left(1+\theta_{1} \mathrm{~L}-\cdots-\theta_{13} L^{13}\right) \varepsilon_{t},
$$

where coefficients of autoregressive is $\phi$, and coefficients of moving average is $\theta$, and $c$ is a constant. Different ways are examined to test the validity of the recommended ARIMA model. For this reason, the ARIMA mode fit, residual plot, histogram plot, and Q-Q plot are obtained. To evaluate the power of the model in Figure $4(a)$, and (b), it shows that the model has good fitting with radon data and the residual distribution plot fluctuates around the mean with some anomalies as in Figure 4 (c), and (d) one can see the histogram (number of repetitions of similar values for residual values regularity changes. The Q-Q graph produces a scatter plot between standard normal quantities with quantities of the input sample. In the sample, the data mostly fit the model with a little diffraction in both tails, which conforms that data fit with same anomalies. In Figure 5, the model data prediction average is shown.

After finding the best model fit to the time series, the ARIMA and the MCS methods can be employed for simulations to get probability distribution of future radon concentration values and identification of all possible future probability values. MCS is also used for time-series data prediction testing part, which consists of $20 \%$ of data in the tail of the time-series data as in Figure 6 . It can be seen that the MCS prediction result has a good fit with real radon data in (Panel A) and four different possible outputs for MCS prediction are shown in (Panel B). The four different possible outputs mean is plotted by the red line with real radon data in the graph, and it has a good fit with it.

\subsection{Analysis of the Relation between Radon Gas and TEC with Earthquakes}

The prediction part of radon data equal, which includes $20 \%$ of all data and MCS results to soil radon data are used in this study based on the earthquake concentration. It is divided into four different groups, where each group includes 15 days for discussion about the relation and influence between soil radon gas and Total Electron Content (TEC) with seismic activity by considering the geomagnetic field activity effect. 


\subsubsection{First Group}

The first group starts from 12 to 27 July 2009 with six micro-earthquake magnitude occurrences as 2.6 3.1. The TEC and radon concentration for the same period are shown in Figure 7.

In the first group, a positive anomaly can be seen in the soil radon concentration and increase over prediction MCS redline value by $40 \mathrm{~Bq} / \mathrm{m}^{3}$, which is related to the first two earthquakes magnitudes, 2.7 and 3 in two days and 18 hours before the event, respectively. The TEC variations for both events are not suitable to count as an anomaly in the range between the upper and lower boundaries (mean \pm two standard deviation) in all stations. Three earthquakes with 3.1, 2.8, and 2.6 magnitudes occurred on 20 July 2009 during 18 hours before earthquakes increasing $\left(50 \mathrm{~Bq} / \mathrm{m}^{3}\right)$ of ${ }^{222} \mathrm{Rn}$ and over the MCS prediction there is an anomaly is related to earthquakes and a short negative anomaly in the TEC can be seen in all stations especially in the nearest one to Ankara TEC station, where one day before is related to events, because of geomagnetic activities are quite well in this period. Last earthquake in this group with $M_{L}=2.7$ during three days before the earthquake, there is an anomaly in the radon sharp increase over the MCS prediction due to the earthquake. In contrast, Total Electron Content uprising on 22 July is not reliable as earthquake anomaly due to variations in the $\left(K_{p}\right.$ and $\left.D_{s t}\right)$ magnitudes as shown in Figure 8 .

From Figure 8, on 22 July 2009, the disturbance in the geomagnetic can be seen as a result of disturbance in the earth's magnetic field, which is caused by the solar wind $\left(K_{p}\right)$ equal to 58 , which is more than 40 and it counted as a quiet condition Disturbance time storms $\left(D_{\text {st }}\right)$ is equal normally to -80 $\mathrm{nT}$ and it should be in the range from 20 to $-20 \mathrm{nT}$ with the source for TEC anomaly in all stations. In the same graph, one can see the density of a solar microwave flux having as $10.7 \mathrm{~cm}$ wavelength value, which is below $70 \mathrm{sfu}$, and hence, the condition is considered as quiet.

\subsubsection{Second Group}

The second group evaluates four earthquakes with other parameters starting from 16 August 2009 to 1 October 2009. The results for TEC variations for three nearest international stations are shown in Figure 9 with radon gas concentration and seismic activities.

In the Figure 9 graph shows that there is no clear and significant pre-seismic or co-seismic anomaly in the ${ }^{222} \mathrm{Rn}$ gas concentration. This may be due to the large distance epicenter with radon station and low magnitude, but after the earthquake $\left(M_{L}=2.7\right)$ there is a post-seismic increase in soil ${ }^{222} R n$ gas concentration. The small uprising can be seen in the TEC peaks on 19, 20, and 22 of August middays due to earthquake $\mathrm{M}_{\mathrm{L}}=3.1$ in 26 August., The increase is clearly that more in the (Ankara city) station compared to other stations. The reason for this small variation in the TEC is the earthquake with low magnitude, pressure production in the ground, which causes to stress generation on rocks and heavily charged ion clusters, distribution in the electric field between ground and atmosphere could be lead to this 
TEC variation in the ionosphere a few days before the earthquake. Another anomaly in the TEC on 30 August can be seen, but this variation is related to geomagnetic variations as shown in Figure 10.

In the Figure 10, all three parameters at (19,20, and 22 of August) have normal values. It approves that the TEC variation source in earthquake $M_{L}=3.1$ on 26 August causes to geomagnetic activities on 30 to 31 August with an increase in the ( $K_{p}$ index) over normal value (40) increasing towards it to (58). The variation in disturbance storm time $\left(D_{\text {st }}\right)$ is under $-20 \mathrm{nT}$ ), with these anomalies in the geomagnetic activity, they are the main factors for ionospheric TEC anomalies on 30 August over the upper bound, which is equal to mean plus two standard deviations $(\mu+2 \sigma)$ as can be seen in all three stations in the midday.

\subsubsection{Third Group}

The third group includes observation radon and TEC data with earthquakes from 30 August to 16 October 2009, which leads to discussion on the relation between parameters as shown in Figure 11.

This group consists of five micro-earthquakes magnitudes between 2.7 to 3.9. According to observations, there is a positive $\mathrm{Rn}$ anomaly on 4,8 , and 10 October with approximate increase $\left(40 \mathrm{~Bq} \mathrm{~m}^{-3}\right)$ over the prediction magnitude estimation by MCS. This variation is counted as a pre-seismic anomaly with 3.9 and 2.8 magnitude earthquakes that occurred on 10 October. For the second series of microseismic events that occurred on 12 October, there is a co-seismic increase in the Rn gas emanated in the soil due to produced pressure on soil pores and the number of micro-cracks increases is helpful to allow radon gas migration. TEC response for seismic events and soil Rn variations under quiet geomagnetic at the period of increasing Rn gas on 4 October, the TEC increased one day after variation Rn gas. There is another anomaly in the TEC Ankara, Tubi, and Istanbul stations on 11 October exactly one day before the second series of seismic events. The effect of this positive anomaly in the TEC in all stations is a seismic activity because the geomagnetic activity for the same time is approximately quiet, and the variations of geomagnetic activity parameters ( $\mathrm{K}_{\mathrm{p}}, \mathrm{D}_{\mathrm{st}}$, and F10.7 flux) are shown in Figure 12.

The geomagnetic activity or ground base due to seismic activity are considered during observations for clarifying the TEC anomalies sources. Variation in the TEC on 4 October can see a small negative anomaly under the lower bound as equal to mean minus two standard deviations $(\mu-2 \sigma)$ in all stations. It is due to increasing soil radon gas at the same time because all three $\left(\mathrm{K}_{\mathrm{p}}, \mathrm{D}_{\mathrm{st}}, \mathrm{F} 10.7\right)$ parameters and are approximately quiet. For the second TEC anomaly on 11 October the seismic events are the main source for these positive anomalies over the upper bound in all stations, because during observations, $K_{p}$ index, F10.7 flux is in the quiet range with a small increase in the $D_{\text {st }}$.

\subsubsection{Fourth Group}


The fourth group includes the observation data from 22 Jan to 7 Feb 2010 and the most powerful seismic events during this study belongs to this group and the effects on the soil radon gas concentration and TEC are presented in Figure 13.

The Alpha meter 611 detector detects an increase $70 \mathrm{~Bq} \mathrm{~m}^{-3}$ in a short time in the $\mathrm{Rn}$ gas concentration 18 hours before the earthquake magnitude $M_{L}=3.4$ on 24 January and sharply decreases after the earthquake to the previous level of concentration. Two days later radon increases 15 hours before the $\mathrm{M}_{\mathrm{L}}=3.3$ magnitude earthquake on 27 January. Both earthquakes create an effect on soil Rn emanation, and TEC positively responds with record anomaly above the upper bound $(\mu+2 \sigma)$, at the same time for Rn variations, but cannot be counted as earthquake precursory due to high solar F10.7 flux.

The most powerful earthquake among all earthquakes is observed in this study magnitude equal to 4.7, which has some aftershocks with magnitudes $3.1,2.9,2.8$, and 2.7 , respectively. The average ${ }^{222} \mathrm{Rn}$ gas increases due to these seismic events at approximately $50 \mathrm{~Bq} \mathrm{~m}^{-3}$ in three days, which is not satisfactory for the measure as an anomaly, but, the epicenter distance to Yolkonak radon station is the main reason for this kind response of radon concentration to seismic events.

The abnormal variation in the ${ }^{222} \mathrm{Rn}$ concentration on 1 February nearly for about five days could be due to earthquake blasts for false recording, high rainfall and snow for the same period, and water was accumulated on the detector as a consequence of flooding at the measurement site; surface sensor severely affected by humidity for short-circuits, by continuation of irregular and unpredictable records up $34000 \mathrm{~Bq} / \mathrm{m}^{3}$ just for $15 \mathrm{~min}$. This kind of records for Alpha Meter detector could only be a possibility in the case of short-circuit occurrence inside the Alpha meter detector. This effect is confirmed in the literature by this article (Thomas et al. 1992).

The variation of TEC in the all-stations path through the upper and lower boundaries on 3 to 4 February is a response for negative variation in the disturbance time storm $\left(D_{s t}\right)$ as in Figure 14.

Results in the Figure 14. show that the abnormal increase in the solar flux F10.7 to the range 77 sfu on 27 January is the primary source for variation in the TEC in all stations, nonetheless other two parameters, namely, $\mathrm{D}_{\mathrm{st}}$ and $\mathrm{K}_{\mathrm{p}}$ index record the normal quite magnitude at the same time.

It can be said that the main source for both positive and negative anomalies in TEC in all stations is due to the disturbance time storms $D_{\text {st }}$ variation, which is equal to $-24 \mathrm{nT}$, and other parameters have the quite normal magnitude in the period.

\subsection{Relation between Lithosphere and Ionosphere}

The relation between soil radon concentration, TEC and seismic activity for all stations are shown in Figure 15. This study discusses all three parameters together for the first time in the literature. 
The peaks are time lag between the ${ }^{222} \mathrm{Rn}$ gas, and the TEC with seismic events. It is important that the anomaly peaks are bigger and wider in stations far from the epicenter, which means that after emanation radon gas by earthquake produced pressure, and it takes some time to affect the ionosphere and TEC. The reason is that the wider peaks are functioned for exchange in the energy and effect between the lithosphere and ionosphere through the seismic events in the preparation period before the main-shock time (Ryu et al. 2014; Shah et al. 2019).

\section{Conclusions}

During the observation period in the study area, only approximately small and medium-size earthquakes have occurred. Results show that a possible good correlation exists between soil ${ }^{222} \mathrm{Rn}$ gas anomalies and micro-seismic activities observations suggest that the soil ${ }^{222} \mathrm{Rn}$ data variations in the study area in NAFZ can be relied on as an earthquake precursor, and they can be useful for predicting future earthquakes.

ARIMA and MCS usage together with detect radon gas anomalies is a rather new method in this field. The proposed ARIMA model and Monte-Carlo forecasts of the soil radon gas data related to micro-earthquake has a significant result and effective finding and estimating other parameters. They are also suitable in forecasting soil radon gas related to macro-earthquake prediction, and other radioactive substances in the environment.

The soil radon gas anomaly amplitude and peak sizes depend on the magnitude of impending earthquakes and the distance to the epicenter. Earthquake magnitude has a positive influence on the radon concentration but the earthquake epicenter depth has a negative impact.

The main source for ionospheric TEC distributions related to the magnetic effects and the distribution can be seen in all the TEC stations, while the distributions due to the micro-seismic events have a lesser extent with smaller impacts.

\section{Declarations}

\section{Acknowledgements}

We would like to thank Boğaziçi Kandilli Observatory (http://www.koeri.boun.edu.tr/scripts/lasteq.asp) for earthquake data, AFAD (Ministry of Interior Disaster and Emergency Management'a Presidency, https://en.afad.gov.tr/) for Rn data, IONOLAB (http://www.ionolab.org/index.php? page=index\&language=en) for TEC data and NASA (www.omniweb.gsfc.nasa.gov) for geomagnetic activity ( $\mathrm{K}_{\mathrm{p}}$-index), disturbance time storm $\left(\mathrm{D}_{\mathrm{st}}\right)$ and solar flux (F10.7).

Funding ('Not applicable')

Conflicts of interest/Competing interests ('Not applicable') 
Availability of data and material (Data can be obtained from the respective web pages.

Code availability ('Not applicable')

\section{References}

1. Akin MK, Kramer SL, Topal T (2016) Dynamic soil characterization and site response estimation for Erbaa, Tokat (Turkey) Natural Hazards 82:1833-1868 doi:https://doi.org/10.1007/s11069-016-22744

2. Akin MK, Topal T, Kramer SL (2013) A newly developed seismic microzonation model of Erbaa (Tokat, Turkey) located on seismically active eastern segment of the North Anatolian Fault Zone (NAFZ) Natural hazards 65:1411-1442 doi:https://doi.org/10.1007/s11069-012-0420-1

3. Arikan F, Erol CB, Arikan O (2003) Regularized estimation of vertical total electron content from Global Positioning System data Journal of Geophysical Research: Space Physics 108 doi:https://doi.org/10.1029/2002JA009605

4. Bayrak Y, Çınar H, Bayrak E (2011) The North Anatolian Fault Zone: an evaluation of earthquake hazard parameters. In: Schattner U (ed) New Frontiers in Tectonic Research. Janeza Trdine 9, 51000 Rijeka, Croatia, pp 269-288

5. Bentley R, Jones J, Lillicrap S (1967) X-ray spectra from accelerators in the range 2 to $6 \mathrm{MeV}$ Physics in Medicine Biology 12:301 doi:https://doi.org/10.1088/0031-9155/12/3/302

6. Bhattarai N, Chapagain NP, Adhikari B (2016) Total electron content and electron density profile observations during geomagnetic storms using COSMIC satellite data 52:1979-1990

7. Box GE, Jenkins GM, Reinsel GC (2011) Time series analysis: forecasting and control vol 734. John Wiley \& Sons,

8. Bozkurt E (2001) Neotectonics of Turkey-a synthesis Geodinamica acta 14:3-30 doi:https://doi.org/10.1080/09853111.2001.11432432

9. Calais E, Minster JB (1995) GPS detection of ionospheric perturbations following the January 17, 1994, Northridge earthquake Geophysical Research Letters 22:1045-1048

doi:https://doi.org/10.1029/95GL00168

10. Cander LR, Mihajlovic S (1998) Forecasting ionospheric structure during the great geomagnetic storms Geophysical Research: Space Physics 103:391-398 doi: https://doi.org/10.1029/97JA02418

11. Cheung Y-W, Lai KS (1995) Lag order and critical values of the augmented Dickey-Fuller test Journal of Business \& Economic Statistics 13:277-280

doi:https://doi.org/10.1080/07350015.1995.10524601

12. Davies K, Baker DM (1965) Ionospheric effects observed around the time of the Alaskan earthquake of March 28, 1964 Geophysical Research 70:2251-2253 doi:

https://doi.org/10.1029/JZ070i009p02251 
13. Farrance I, Frenkel R (2014) Uncertainty in measurement: a review of Monte Carlo simulation using Microsoft Excel for the calculation of uncertainties through functional relationships, including uncertainties in empirically derived constants The Clinical Biochemist Reviews 35:37

14. Friedmann H (2012) Radon in earthquake prediction research Radiat Prot Dosimetry 149:177-184 doi:https://doi.org/10.1093/rpd/ncr229

15. Ghosh D, Deb A, Sengupta R (2009) Anomalous radon emission as precursor of earthquake Applied Geophysics 69:67-81 doi:https://doi.org/10.1016/j.jappgeo.2009.06.001

16. Gokhberg M (1983) Strong acoustic wave action ESASP 195:99-110

17. Guo J, Li W, Yu H, Liu Z, Zhao C, Kong Q (2015) Impending ionospheric anomaly preceding the Iquique Mw8. 2 earthquake in Chile on 2014 April 1 Geophysical Supplements to the Monthly Notices of the Royal Astronomical Society 203:1461-1470 doi:https://doi.org/10.1093/gji/ggv376

18. Ho CC, Ting C-Y (2015) Time series analysis and forecasting of dengue using open data International Visual Informatics Conference:51-63 doi:https://doi.org/10.1007/978-3-319-25939-0_5

19. Hobijn B, Franses PH, Ooms M (2004) Generalizations of the KPSS-test for stationarity Statistica Neerlandica 58:483-502 doi:https://doi.org/10.1111/j.1467-9574.2004.00272.x

20. Kamislioglu M, Külahcı F (2014) Investigation nonlinear behavior of radon gas (222 Rn) 2014 22nd Signal Processing and Communications Applications Conference (SIU):208-211 doi:https://doi.org/10.1109/SIU.2014.6830202

21. Kamislioğlu M, Külahcı F (2016) Chaotic behavior of soil Radon gas and applications Acta Geophysica 64:1563-1592 doi:https://doi.org/10.1515/acgeo-2016-0077

22. Külahcı $F$ (2020) Environmental distribution and modelling of radioactive lead (210): a Monte Carlo simulation application Lead in Plants and the Environment:15-32 doi:https://doi.org/10.1007/978-3030-21638-2_2

23. Külahcı F, Aközcan S, Günay O (2020) Monte Carlo simulations and forecasting of Radium-226, Thorium-232, and Potassium-40 radioactivity concentrations Radioanalytical Nuclear Chemistry:1-16 doi:https://doi.org/10.1007/s10967-020-07059-y

24. Külahcı F, Çiçek Ş (2015) Time-series analysis of water and soil radon anomalies to identify micro, macro earthquakes Arabian Journal of Geosciences 8:5239-5246 doi:https://doi.org/10.1007/s12517-014-1513-9

25. Külahcı F, Şen Z (2014) On the correction of spatial and statistical uncertainties in systematic measurements of $222 \mathrm{Rn}$ for earthquake prediction Surveys in Geophysics 35:449-478 doi: https://doi.org/10.1007/s10712-013-9273-8

26. Kuo T, Lin C, Su C, Liu C, Lin CH, Chang C, Chiang C (2011) Correlating recurrent radon precursors with local earthquake magnitude and crust strain near the Chihshang fault of eastern Taiwan Natural hazards 59:861-869 doi:https://doi.org/10.1007/s11069-011-9800-1

27. Kwiatkowski D, Phillips PCB, Schmidt P, Shin Y (1992) Testing the null hypothesis of stationarity against the alternative of a unit root: How sure are we that economic time series have a unit root? Journal of Econometrics 54:159-178 doi:https://doi.org/10.1016/0304-4076(92)90104-Y 
28. Le H, Liu L, Liu J-Y, Zhao B, Chen Y, Wan W (2013) The ionospheric anomalies prior to the M9.0 Tohoku-Oki earthquake J Asian Earth Sci 62:476-484 doi:https://doi.org/10.1016/j.jseaes.2012.10.034

29. Leonard RS, Barnes Jr R (1965) Observation of ionospheric disturbances following the Alaska earthquake Geophysical Research 70:1250-1253 doi:https://doi.org/10.1029/JZ070i005p01250

30. Leybourne SJ, McCabe BPM (1994) A consistent test for a unit root Journal of Business \& Economic Statistics 12:157-166

31. Liperovsky V, Pokhotelov O, Meister C-V, Liperovskaya E (2008) Physical models of coupling in the lithosphere-atmosphere-ionosphere system before earthquakes J Geomagnetism Aeronomy 48:795806 doi:https://doi.org/10.1134/S0016793208060133

32. Md Yusoff SH, Hwee San L (2016) Observation of vertical electron density profile in inospheric physics Earth and Space 42:43-47

33. Menvielle M, Berthelier A (1991) The K-derived planetary indices: Description and availability Reviews of Geophysics 29:415-432 doi:https://doi.org/10.1029/91RG00994

34. Miyaki K, Hayakawa M, Molchanov $O$ (2002) The role of gravity waves in the lithosphere-ionosphere coupling, as revealed from the subionospheric LF propagation data Seismo Electromagnetics: Lithosphere-Atmosphere-lonosphere Coupling:229-232

35. Muhammad A, Külahcı F, Akram P (2020) Modeling radon time series on the North Anatolian Fault Zone, Turkiye: Fourier transforms and Monte Carlo simulations Natural Hazards 104:979-996 doi:https://doi.org/10.1007/s11069-020-04200-8

36. Nayir H, Arikan F, Arikan O, Erol C (2007) GPS/TEC estimation with IONOLAB method 2007 3rd International Conference on Recent Advances in Space Technologies:29-34 doi:https://doi.org/10.1109/RAST.2007.4283998

37. Nazaroff WW, Nero AV (1988) Radon and its decay products in indoor air vol 21. John Wiley and Sons Inc, United States

38. Papastefanou C (2007) Measuring radon in soil gas and groundwaters: a review Annals of geophysics 50:569-578

39. Rikitake T (1968) Earthquake prediction Earth-Science Reviews 4:245-282 doi:https://doi.org/10.1016/0012-8252(68)90154-2

40. Ryu K, Parrot M, Kim S-G, Jeong K, Chae J, Pulinets S, Oyama KI (2014) Suspected seismoionospheric coupling observed by satellite measurements and GPS TEC related to the M7. 9 Wenchuan earthquake of 12 May 2008 Geophysical Research: Space Physics 119:10,305-310,323 doi:https://doi.org/10.1002/2014JA020613

41. Scholz CH (2019) The mechanics of earthquakes and faulting. Cambridge university press. doi:https://doi.org/10.1017/9781316681473

42. Sezen U, Arikan F, Arikan O, Ugurlu O, Sadeghimorad A (2013) Online, automatic, near-real time estimation of GPS-TEC: IONOLAB-TEC Space Weather 11:297-305 doi:https://doi.org/10.1002/swe.20054 
43. Shah M, Tariq MA, Ahmad J, Naqvi NA, Jin S (2019) Seismo ionospheric anomalies before the 2007 M7. 7 Chile earthquake from GPS TEC and DEMETER J Journal of Geodynamics 127:42-51 doi:https://doi.org/10.1016/j.jog.2019.05.004

44. Simha CP et al. (2014) lonospheric disturbances with the time of occurrence, magnitude and location of the earthquake (M6. 5) near the Indian subcontinent Natural hazards 70:935-940 doi:https://doi.org/10.1007/s11069-013-0816-6

45. Singh M, Kumar M, Jain R, Chatrath R (1999) Radon in ground water related to seismic events Radiation Measurements 30:465-469 doi:https://doi.org/10.1016/S1350-4487(99)00049-9

46. Spruit H, Roberts B (1983) Magnetic flux tubes on the sun Nature 304:401-406 doi:https://doi.org/10.1038/304401a0

47. Tariq MA, Shah M, Hernández-Pajares M, Iqbal TJAiSR (2019) Pre-earthquake ionospheric anomalies before three major earthquakes by GPS-TEC and GIM-TEC data during 2015-2017 63:2088-2099 doi:https://doi.org/10.1016/j.asr.2018.12.028

48. Thomas D, Cotter J, Holford D (1992) Experimental design for soil gas radon monitoring radioanalyticalmnuclear chemistry 161:313-323 doi:https://doi.org/10.1007/bf02040478

49. Ulomov VI, Mavashev B A precursor of a strong tectonic earthquake. In: Doklady Akademii Nauk, 1967. vol 2. Russian Academy of Sciences, pp 319-321

50. Ulomov VI, Zakharova Al, Ulomova N The Tashkent earthquake of April 26, 1966, and its repeated shocks. In: Doklady Akademii Nauk, 1967. vol 3. Russian Academy of Sciences, pp 567-570

51. Xia C, Wang Q, Yu T, Xu G, Yang S (2011) Variations of ionospheric total electron content before three strong earthquakes in the Qinghai-Tibet region Advances in space research 47:506-514 doi:https://doi.org/10.1016/j.asr.2010.09.006

\section{Figures}




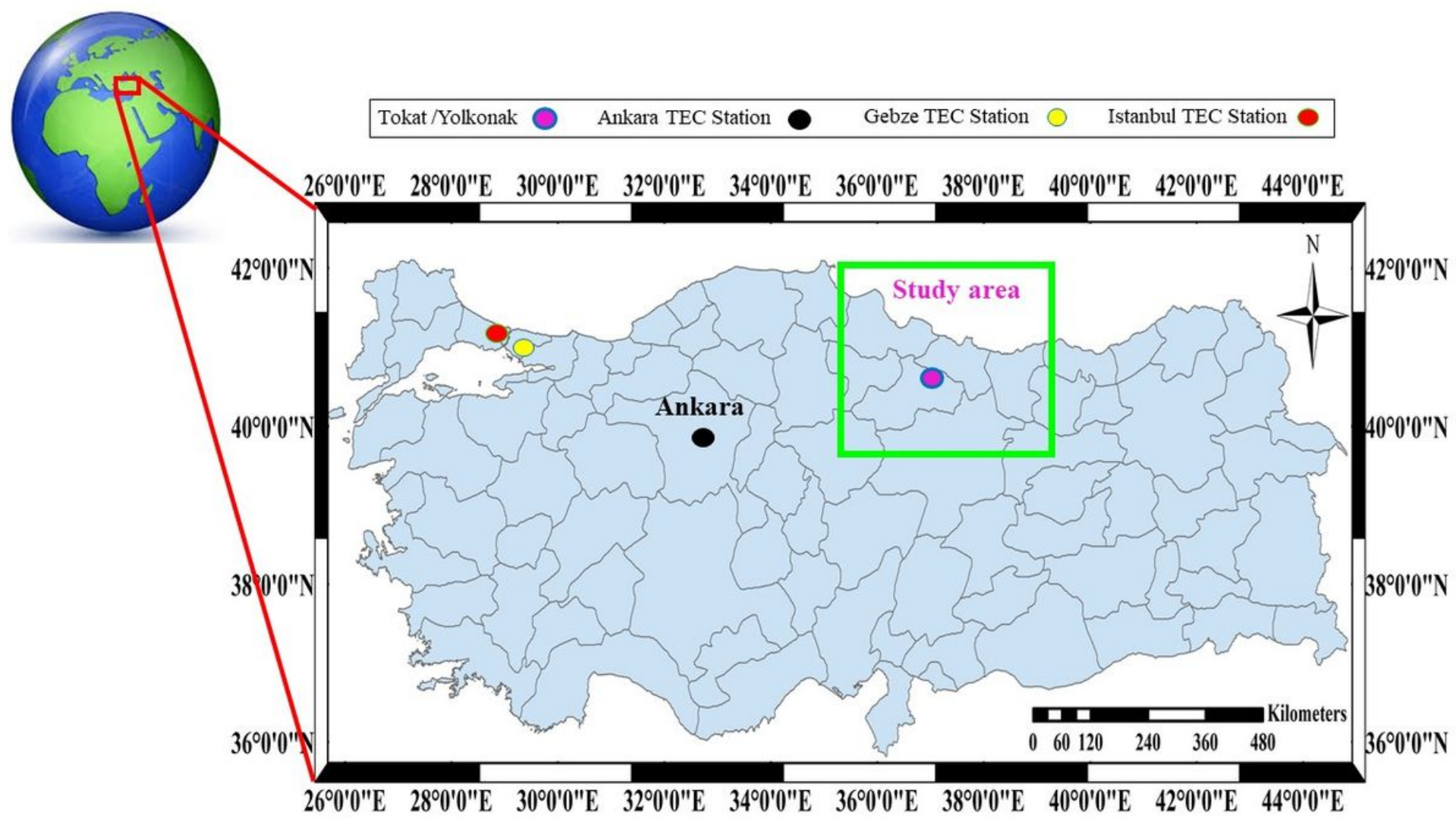

\section{Figure 1}

Study area, Total Electron Content stations and Tokat/Yolkonak soil Rn station. Note: The designations employed and the presentation of the material on this map do not imply the expression of any opinion whatsoever on the part of Research Square concerning the legal status of any country, territory, city or area or of its authorities, or concerning the delimitation of its frontiers or boundaries. This map has been provided by the authors. 


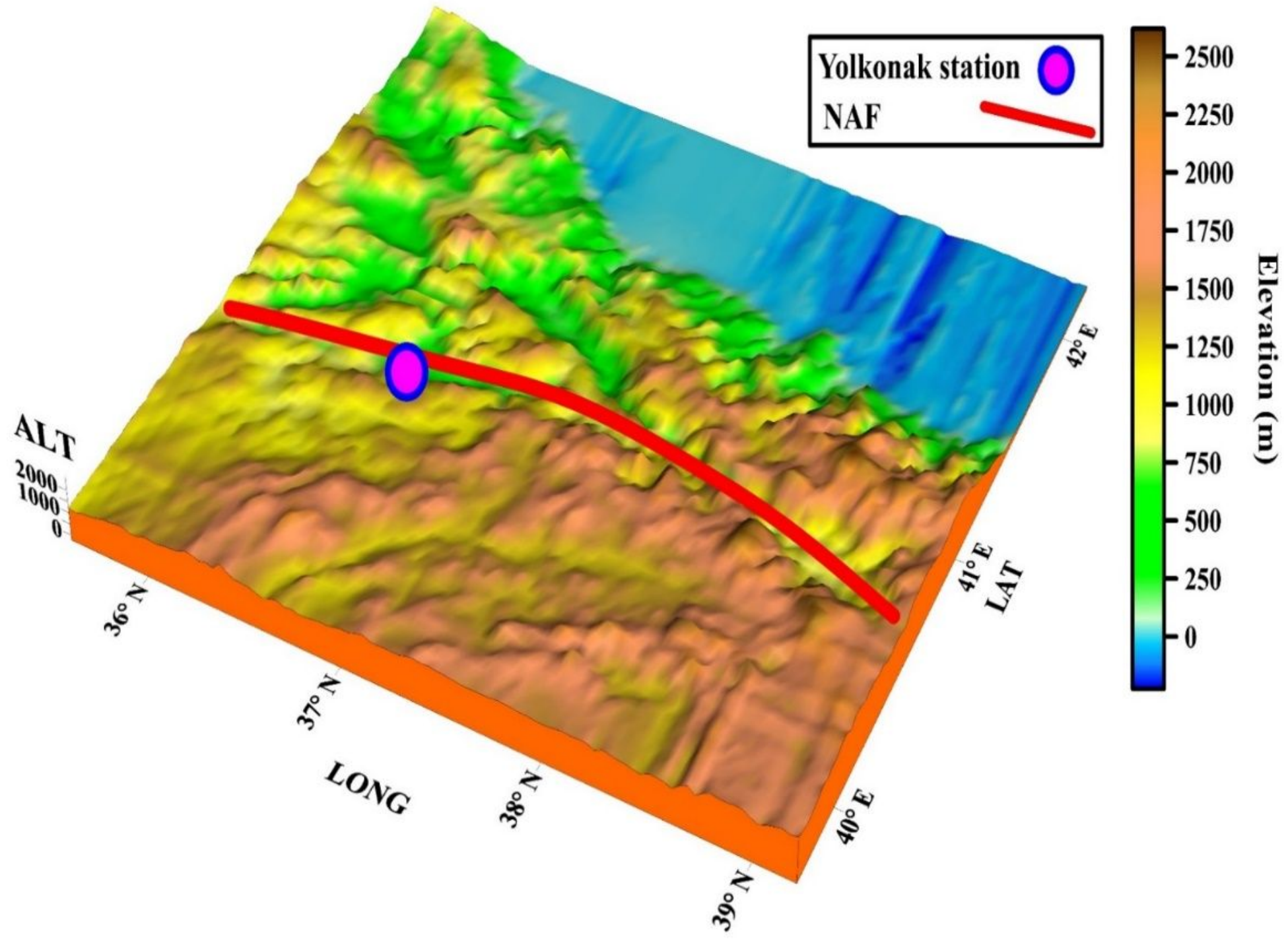

Figure 2

3D representation of the work area. Note: The designations employed and the presentation of the material on this map do not imply the expression of any opinion whatsoever on the part of Research Square concerning the legal status of any country, territory, city or area or of its authorities, or concerning the delimitation of its frontiers or boundaries. This map has been provided by the authors. 


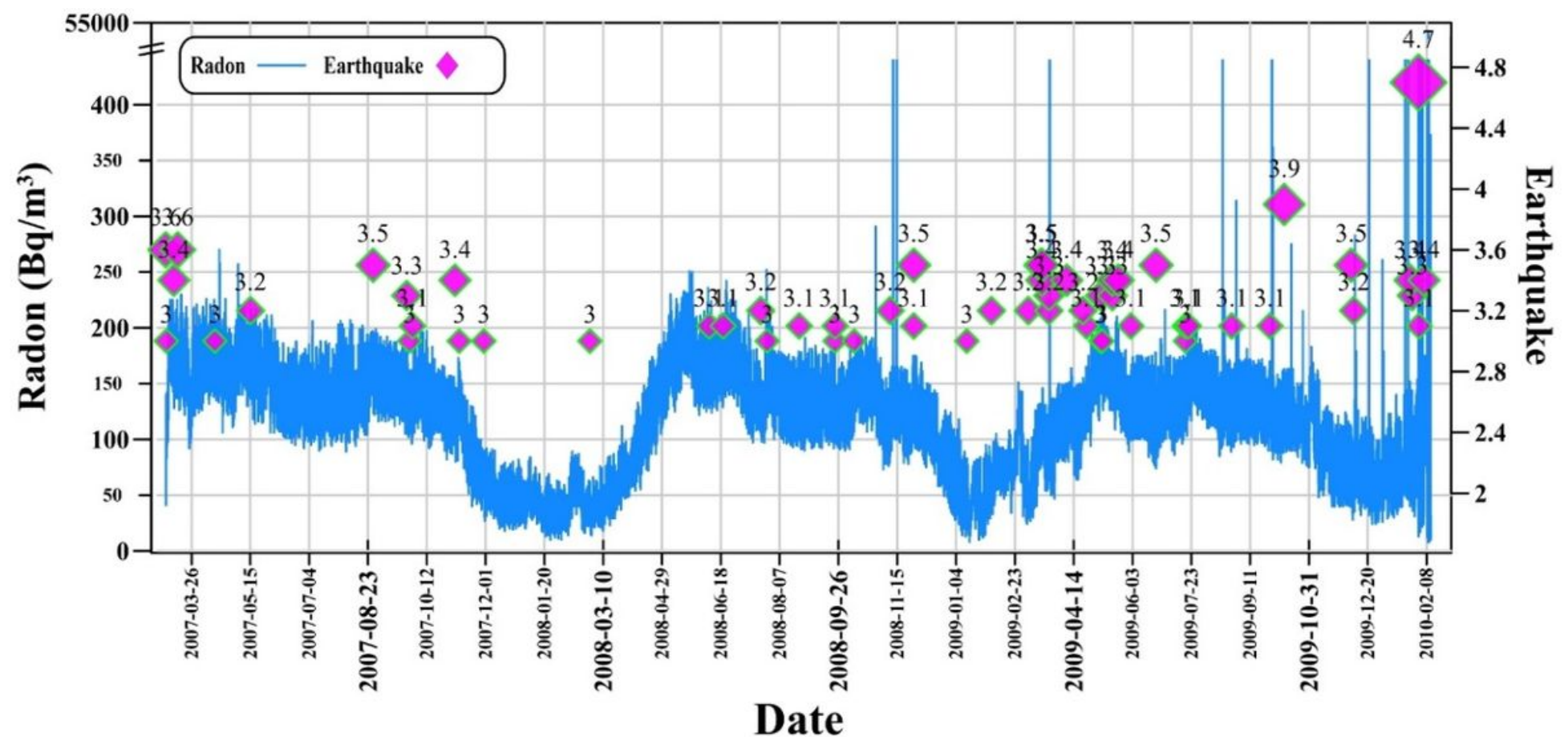

Figure 3

Soil 222Rn concentration levels and seismic activity in the study period time. 

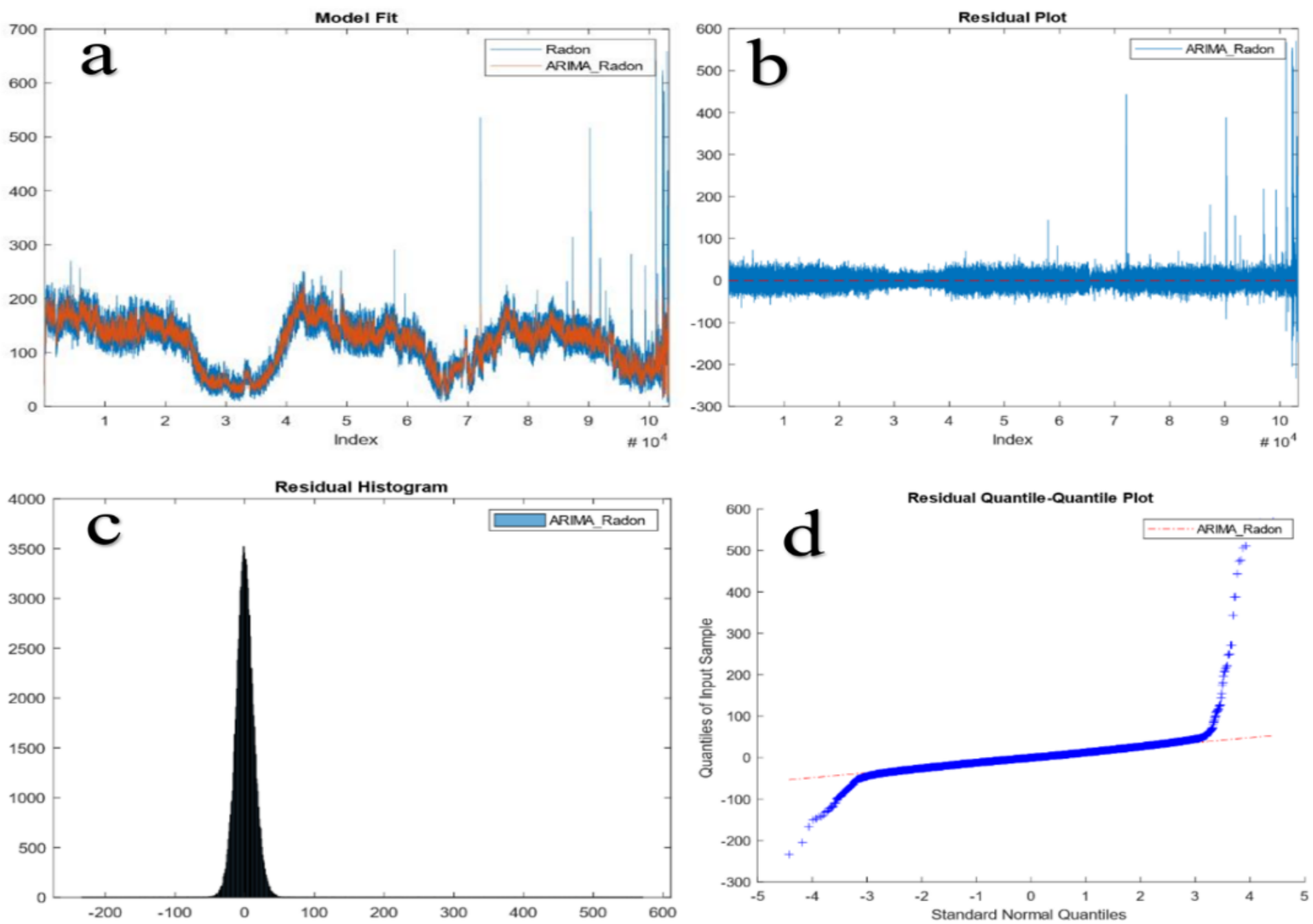

Figure 4

(a) Model fit, (b) residual plot, (c) histogram plot, and (d) Q-Q plot for radon ARIMA model. 


\section{Radon-differenced Time Series Forecast}

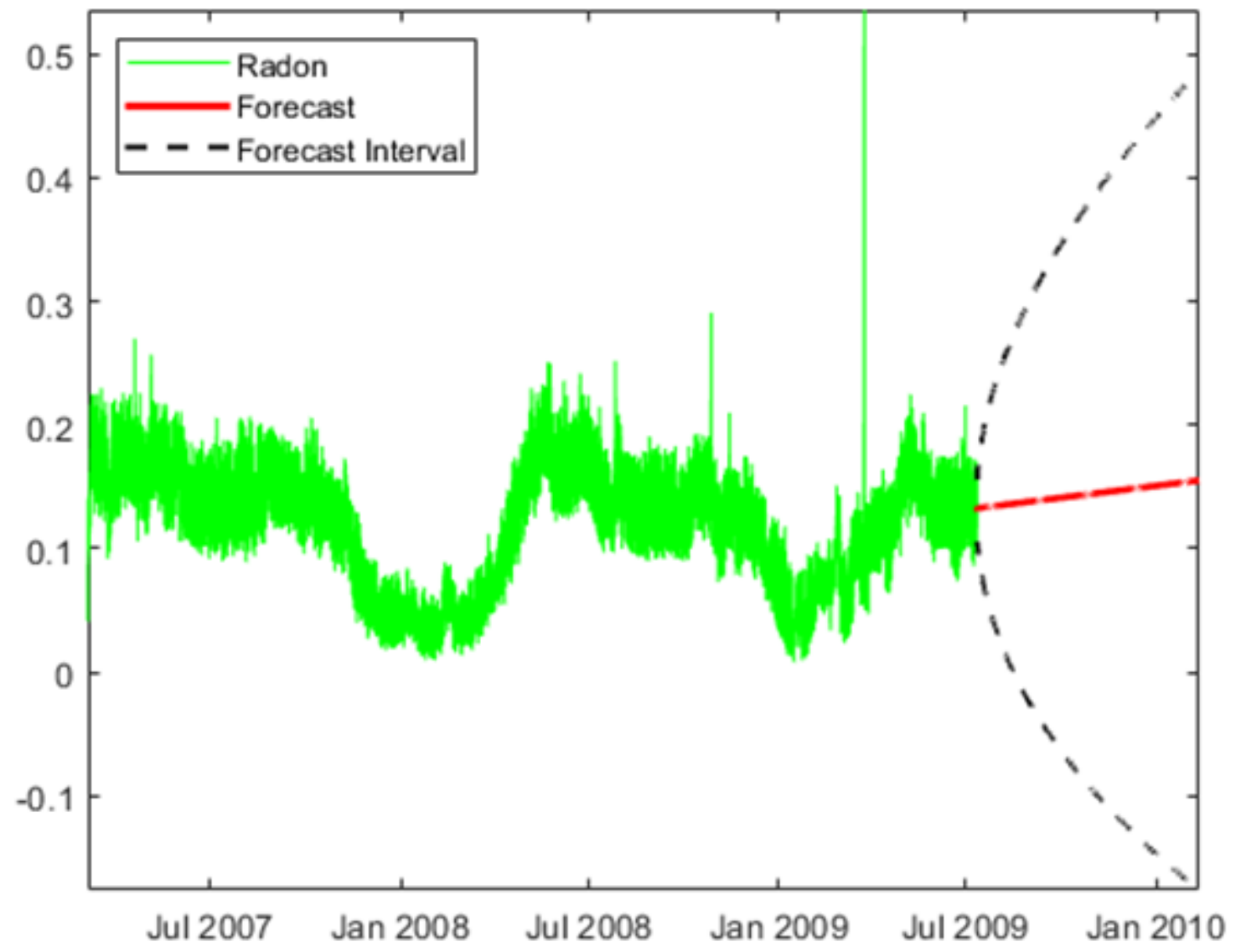

Figure 5

ARIMA $(8,1,13)$ model prediction for radon data. 


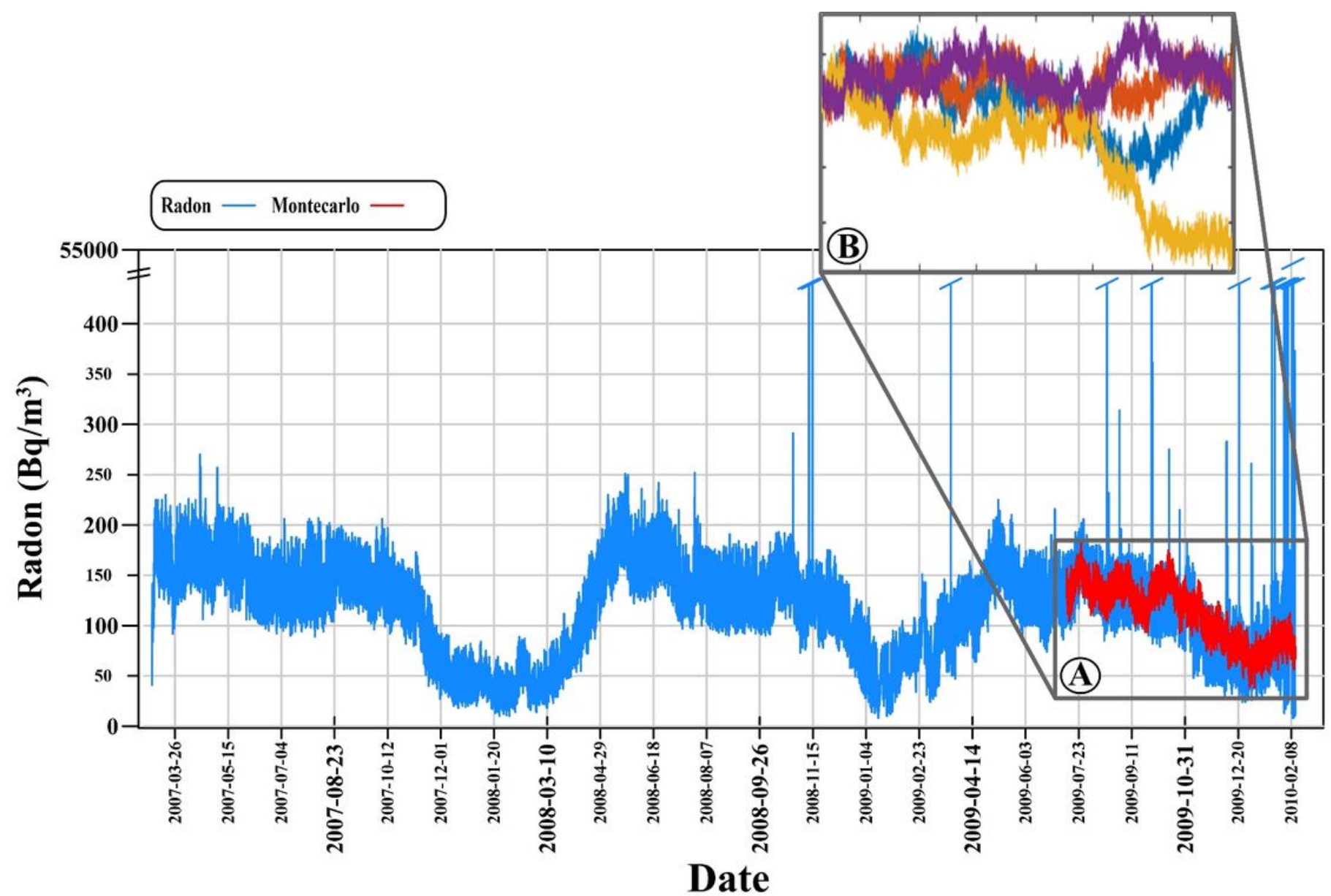

Figure 6

Monte Carlo simulation of soil Rn gas and comparison of real soil Rn gas data. The changes shown in red in the graph are the results from the Monte Carlo simulation result (Panel A). Panel B describes the detailed view of many MCS curves before averaging. 


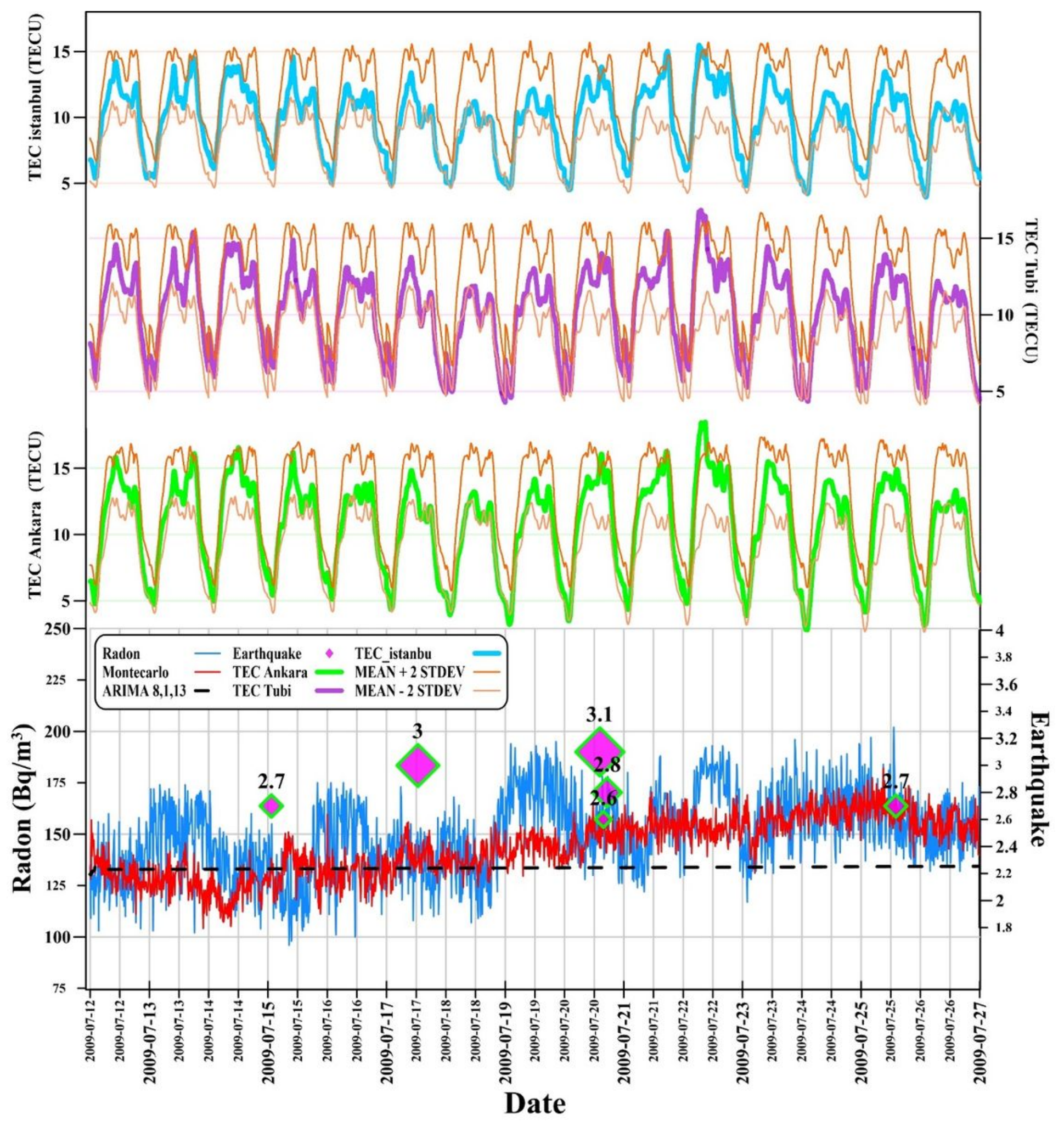

Figure 7

Simultaneous variation of concentration levels of soil Rn concentrations, TEC, and earthquakes and soil Rn gas by ARIMA and MCS modeling (First Group) 


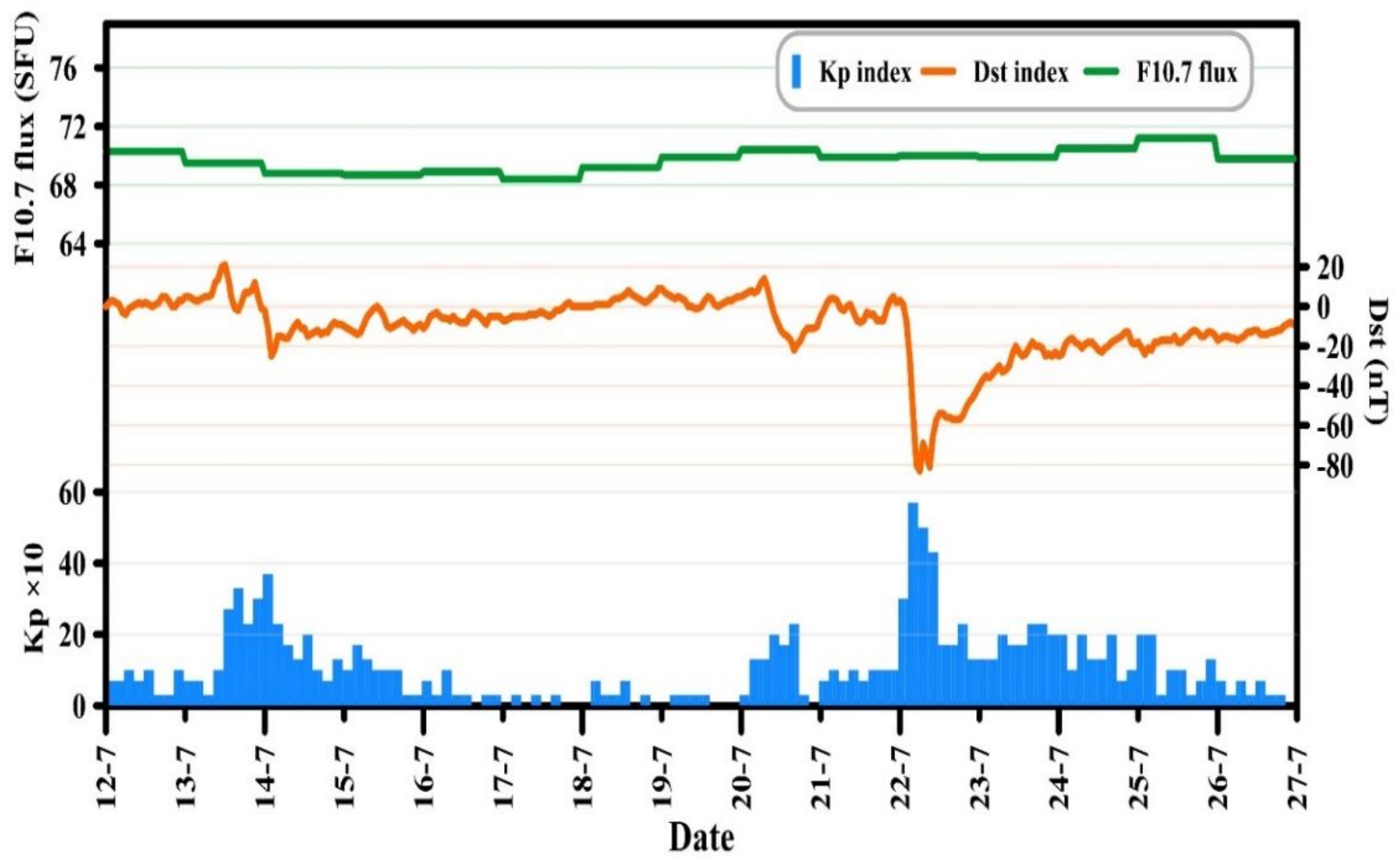

Figure 8

Kp index, disturbance solar time (Dst), F10.7 flux for the first group 


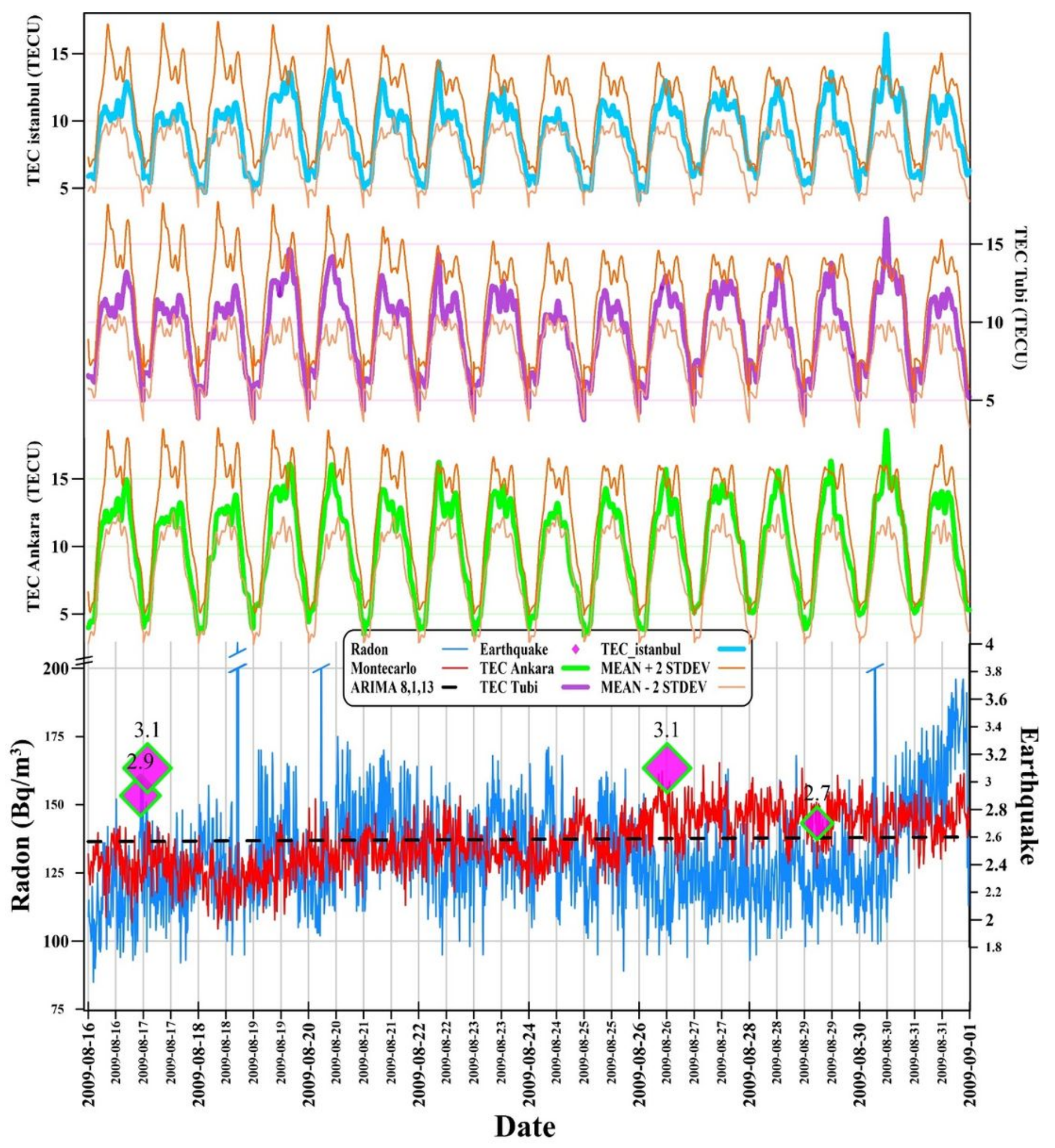

Figure 9

Simultaneous variation of concentration levels of soil Rn concentrations, TEC, and earthquakes and soil Rn gas by ARIMA and MCS modeling (Second Group) 


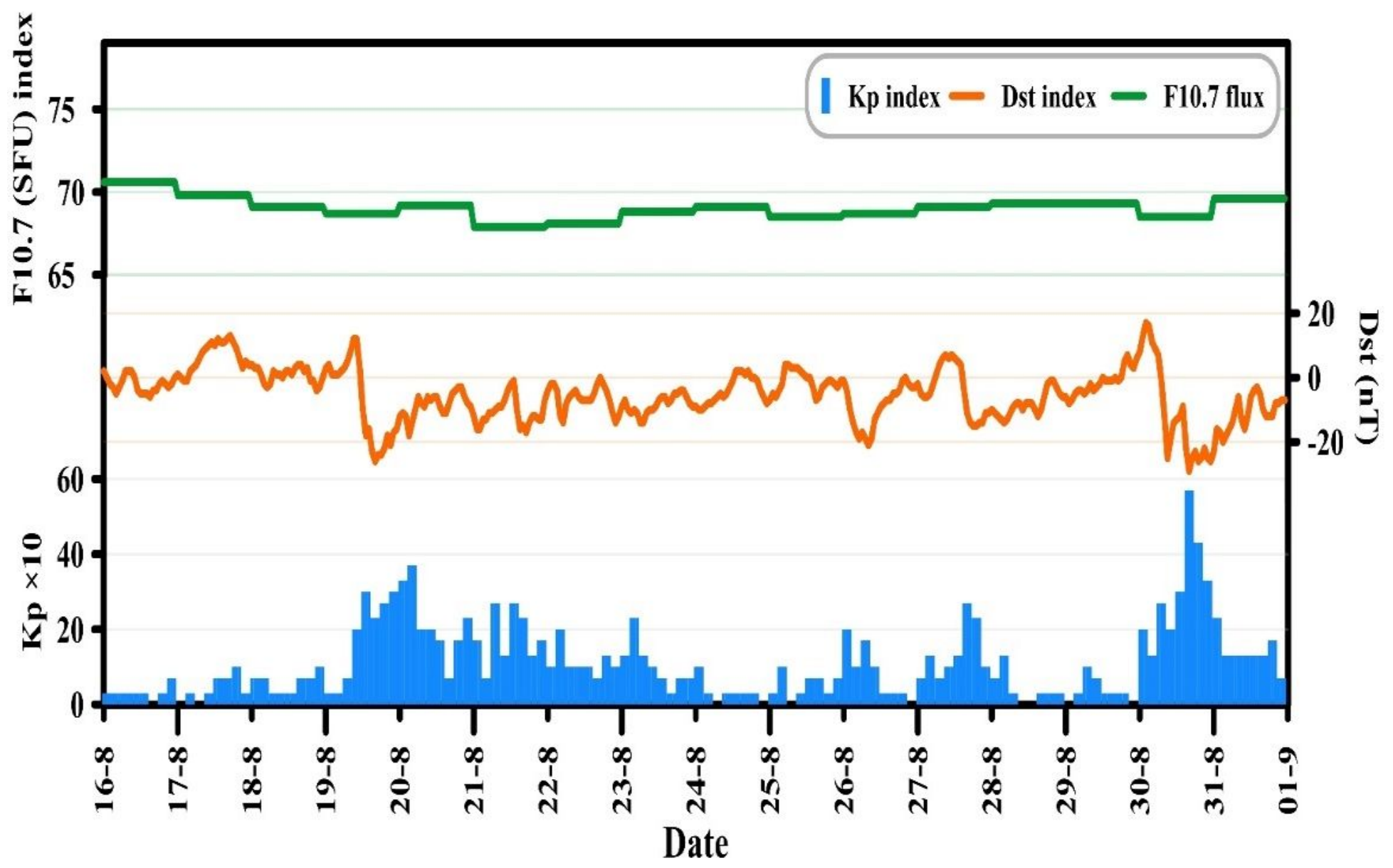

Figure 10

Kp index, disturbance solar time (Dst), F10.7 flux for the second group 


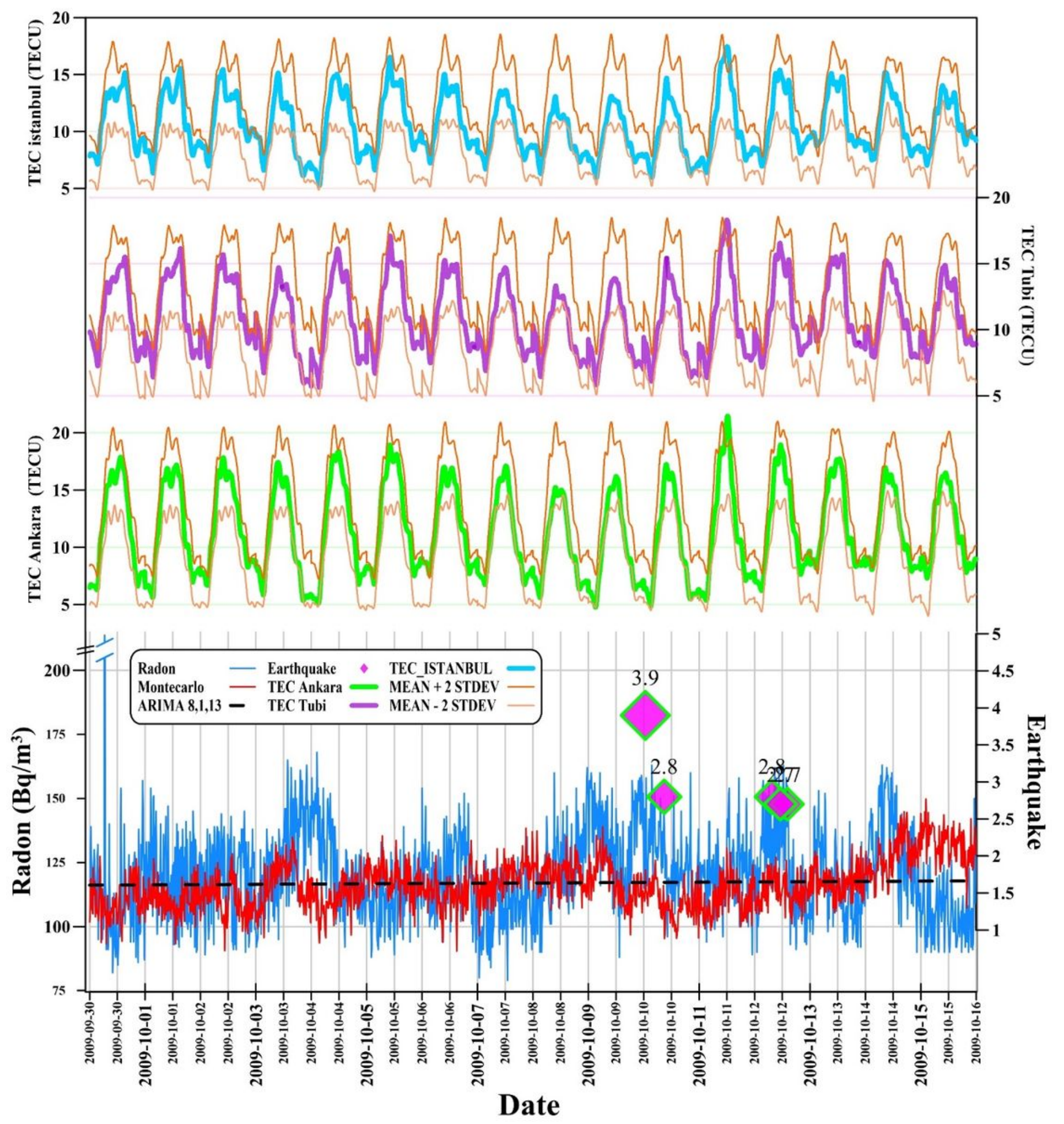

Figure 11

Simultaneous variation of concentration levels of soil Rn concentrations, TEC, and earthquakes and soil Rn gas by ARIMA and MCS modeling (Third Group) 


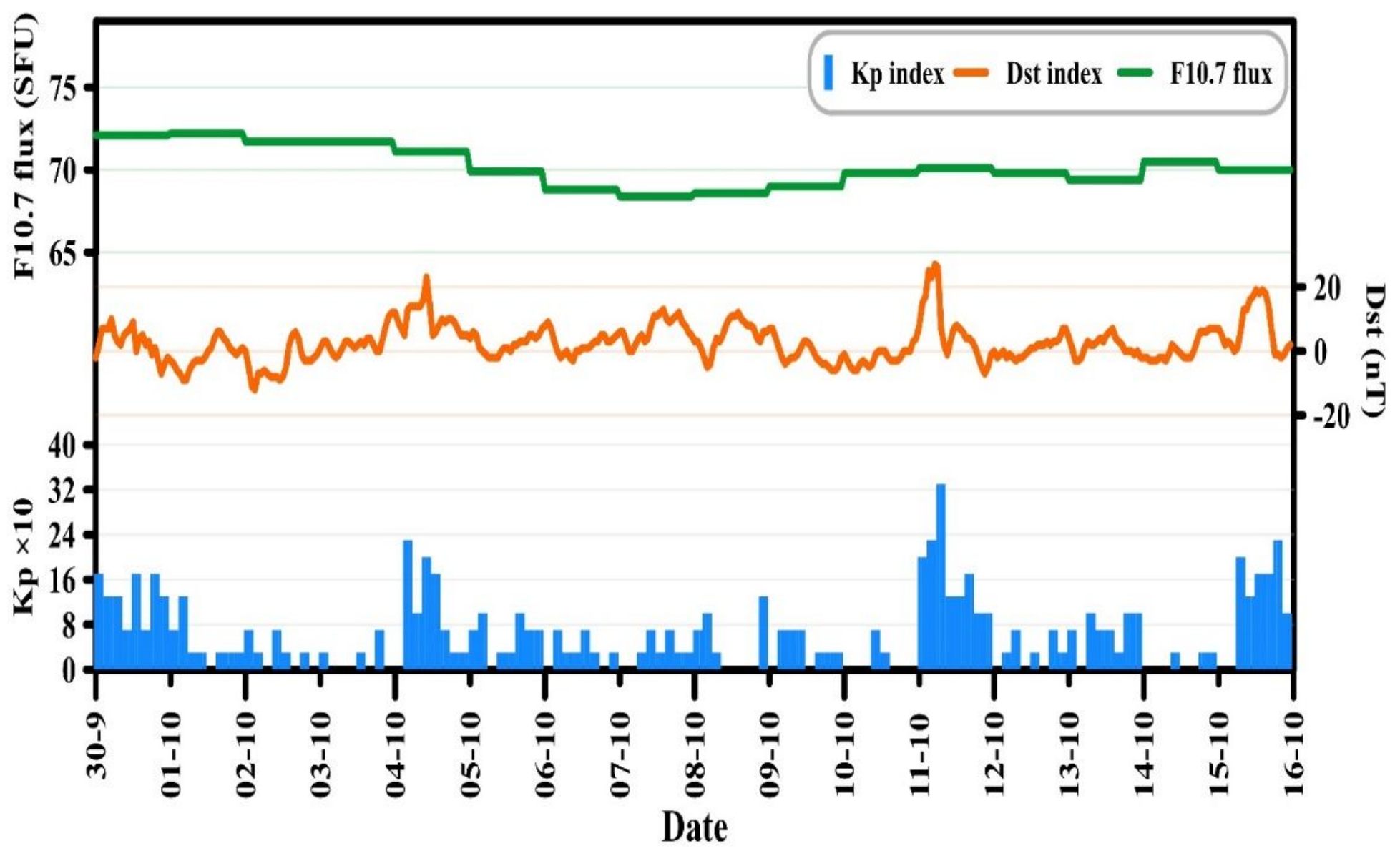

Figure 12

Kp index, disturbance solar time (Dst), F10.7 flux for the third group 


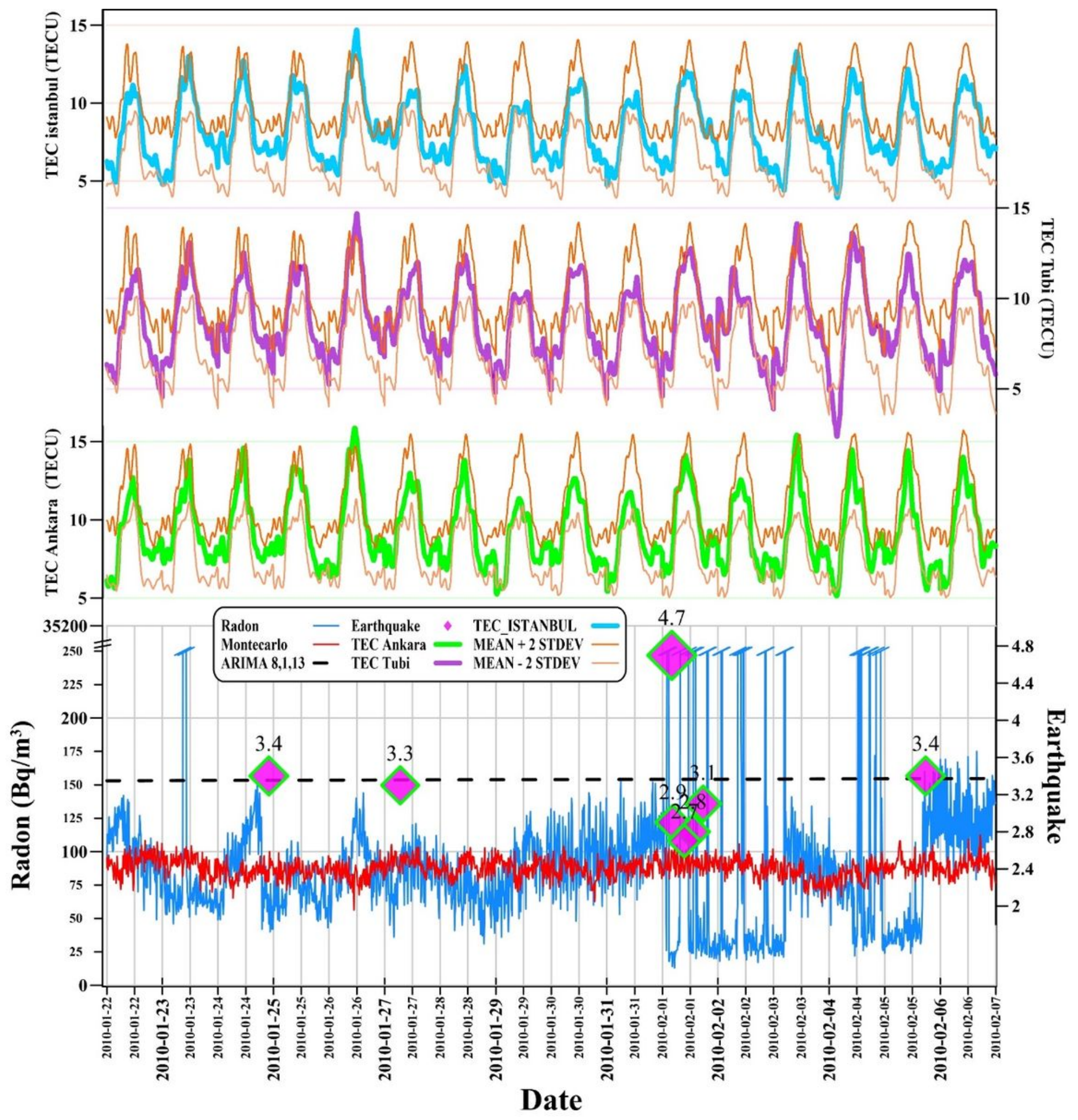

Figure 13

Rn concentration, ARIMA with MCS for radon gas, TEC, and earthquakes for the fourth group 


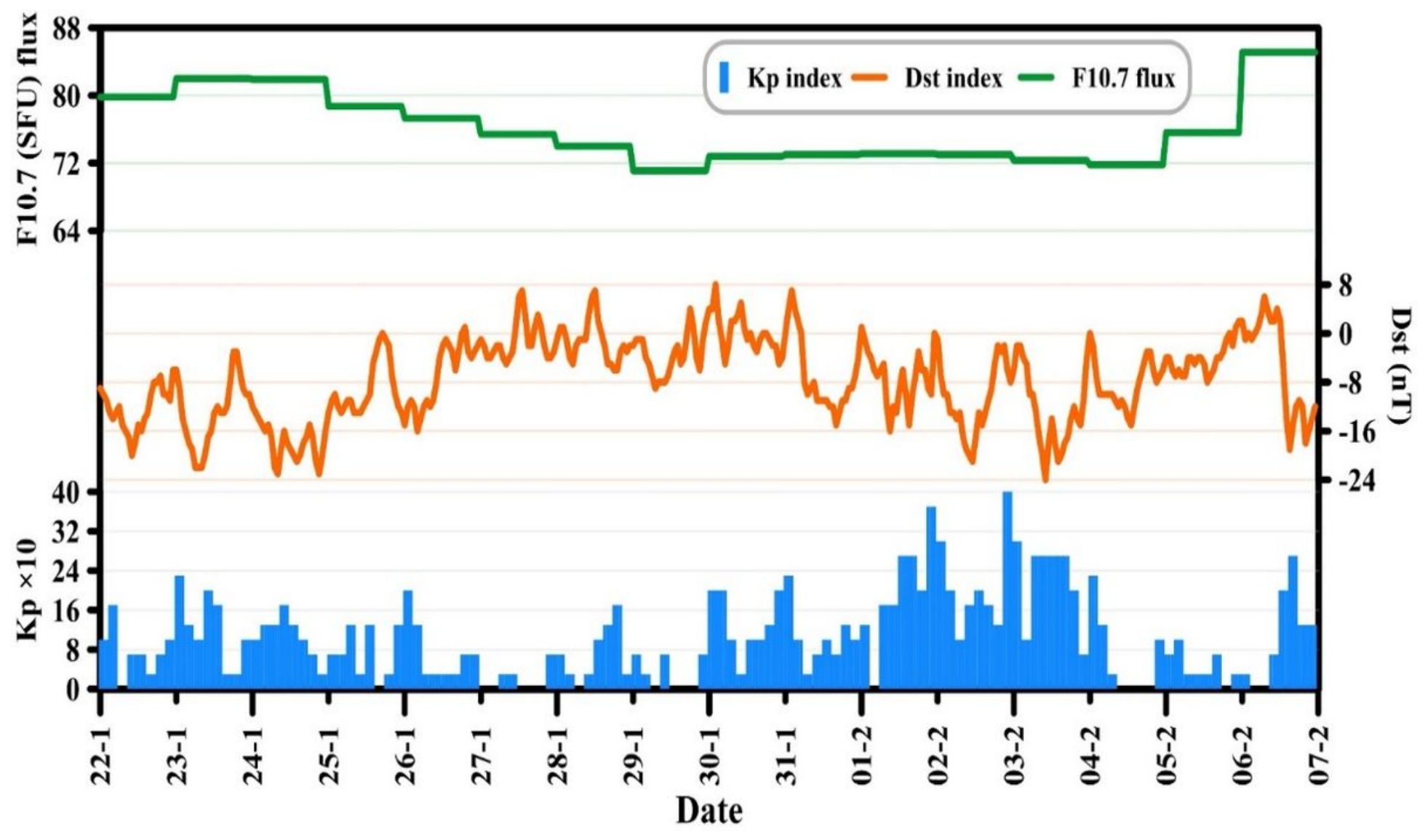

Figure 14

Kp index, disturbance solar time (Dst), F10.7 flux for the fourth group 


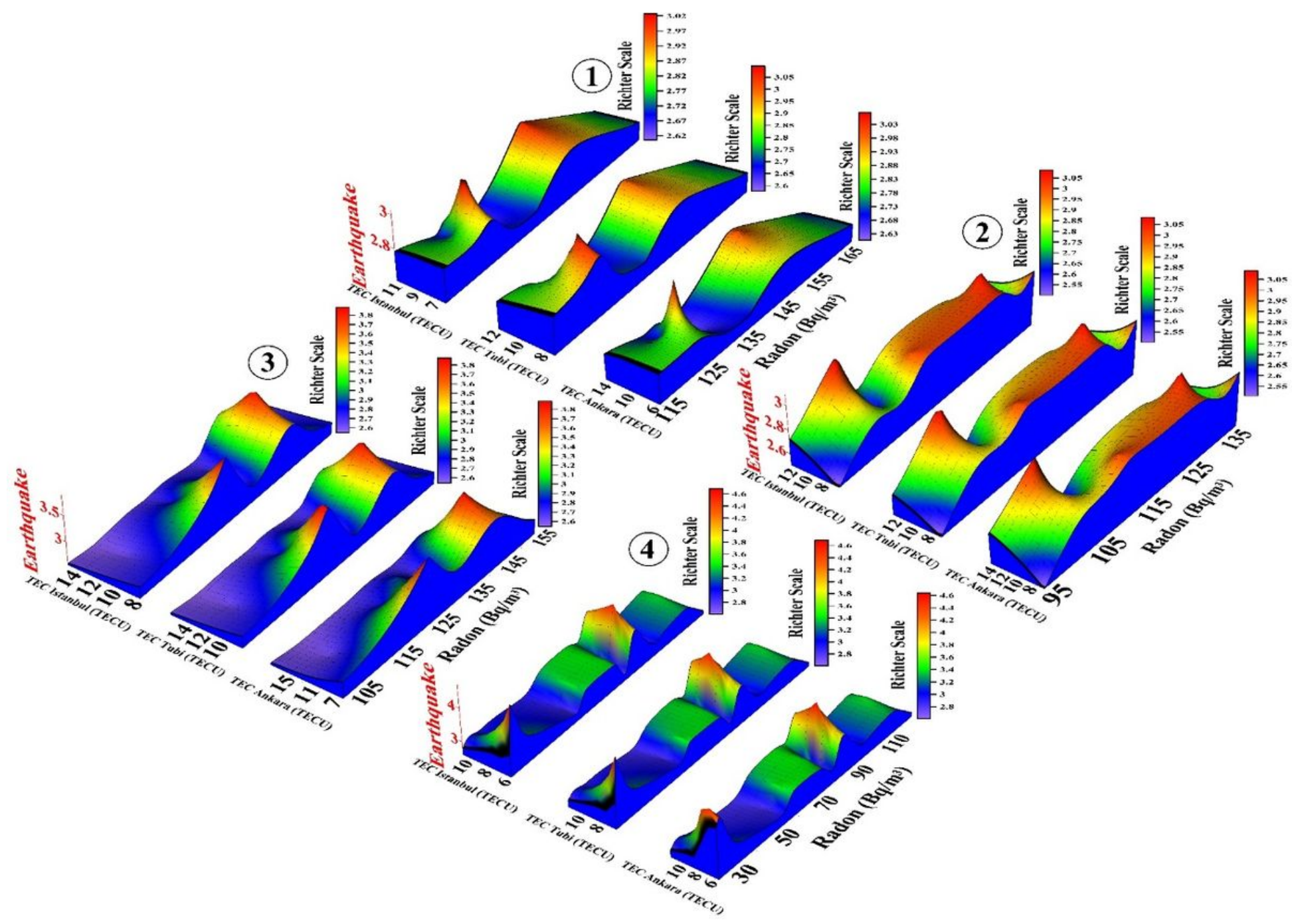

Figure 15

The relation between soil radon concentration and Total Electron Content (TEC) and earthquakes. 